\title{
Severe combined immunodeficiency with abnormalities in expression of the common leucocyte antigen, CD45
}

\author{
Catherine M Cale, Nigel J Klein, Vas Novelli, Paul Veys, Alison M Jones, Gareth Morgan
}

\begin{abstract}
Children presenting with disseminated viral infections should be carefully investigated because they almost invariably have an underlying immunodeficiency. A child is reported who had disseminated cytomegalovirus and a novel form of severe co-mbined immunodeficiency with abnormal expression of the common leucocyte antigen, CD45.

(Arch Dis Child 1997;76:163-164)
\end{abstract}

Keywords: severe combined immunodeficiency; CD45.

Department of

Immunology and

Infectious Diseases,

Great Ormond Street

Hospital NHS Trust,

Great Ormond Street,

London WC1N 3JH

C M Cale

N J Klein

V Novelli

P Veys

A $M$ Jones

G Morgan

Correspondence to:

Dr Cale.

Accepted

16 September 1996

Disseminated cytomegalovirus presenting in a previously well child is extremely rare and is almost invariably associated with a deficiency of cell mediated immunity. We report a child who presented in infancy with cytomegalovirus and was found to have a novel immunodeficiency.

\section{Case report}

The first child of consanguineous Turkish parents presented aged 2 months with a rash, pyrexia, hepatosplenomegaly, lymphadenopathy, pneumonitis, and pancytopenia. Cytomegalovirus was detected in buffy coats, a liver biopsy specimen, nasopharyngeal aspirates, and urine. HIV-1 and HIV-2 antibody testing was negative. On the basis of immunological investigations (see below) and clinical phenotype, a diagnosis of severe combined immunodeficiency (SCID) with postnatally acquired cytomegalovirus was made. She responded well to anticytomegalovirus treatment and aged 8 months underwent bone marrow transplantation (BMT) from a matched unrelated donor. $\mathrm{T}$ cell engraftment was demonstrated three weeks after BMT. Despite continuous anticytomegalovirus treatment (gancyclovir, foscarnet, cytomegalovirus hyperimmune immuoglobulin) her cytomegalovirus reactivated and she died 55 days after BMT.

\section{Immunological investigations}

Analysis of lymphocyte subsets showed (normal ranges are shown in brackets): absolute lymphopenia, $1.74 \times 10^{9} / 1\left(2.7-5.4 \times 10^{9} / 1\right)$; low $\mathrm{T}$ cell numbers, $0.26 \times 10^{9} / 1\left(1.7-3.6 \times 10^{9} / 1\right)$; markedly low CD4+, $0.07 \times 10^{9} / 1(1.7-2.8 \times$ $\left.10^{9} / 1\right)$; low CD $8+, 0.36 \times 10^{9} / 1\left(0.8-1.2 \times 10^{9} / 1\right)$; and normal $\mathrm{B}$ cell numbers, $1.2 \times 10^{9} / 1$ $\left(0.5-1.5 \times 10^{9} / 1\right)$.

Immunoglobulin production was impaired, with low concentrations for age of $\operatorname{IgM}$ and IgA. Some IgM production was detected in the
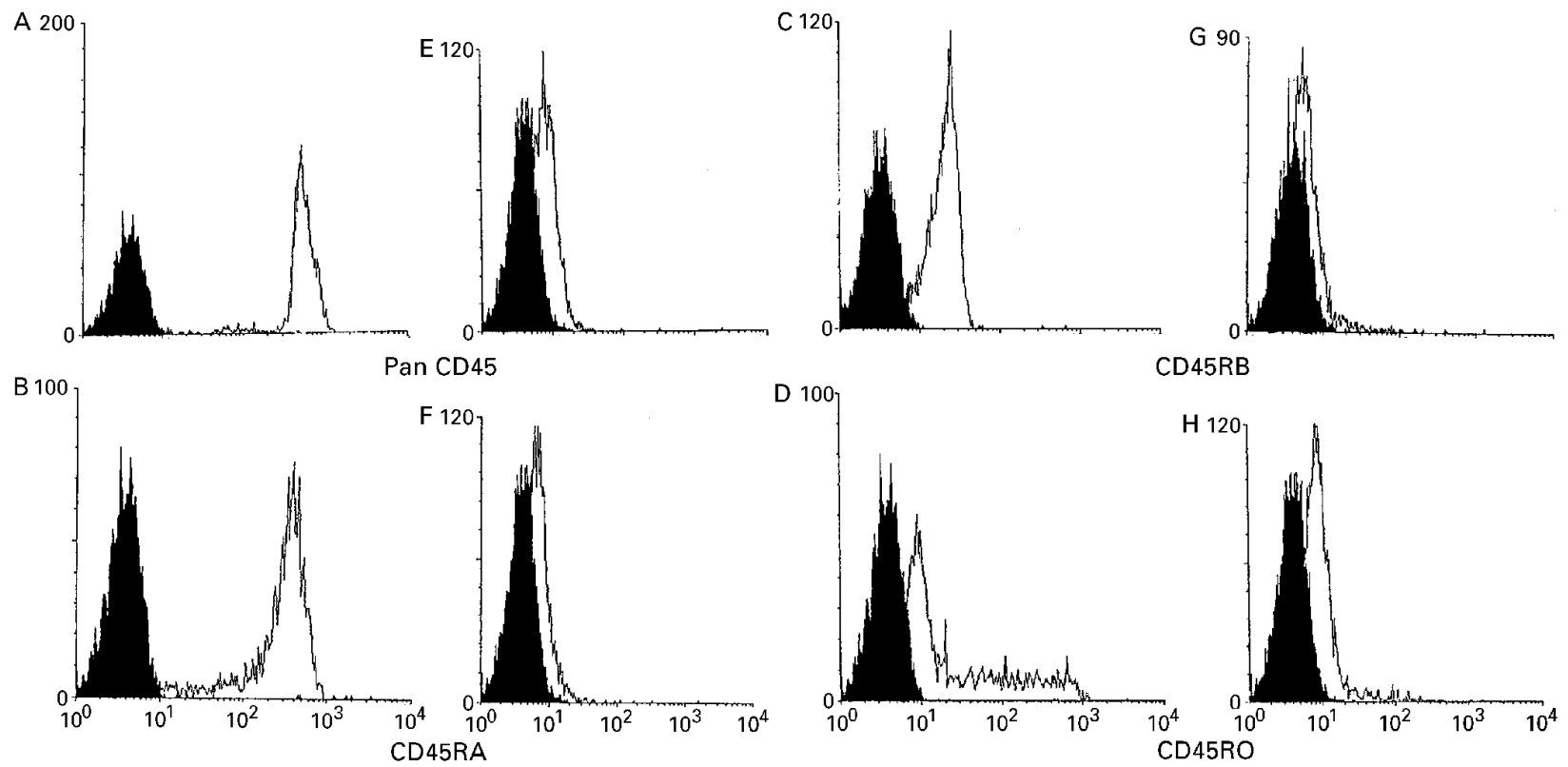

Figure 1 Lymphocytes from control (panels $A-D$ ) and the patient (panels $E-H$ ) were analysed by flow cytometry using a variety of monoclonal antibodies. All x axes show median fluorescence intensity, and y axes show cell numbers. Solid curves indicate background from isotope matched antibodies, and empty curves show fluorescence of the specific monoclonal antibody. Low concentrations of a pan $C D 45$ marker ( $A, E), R A(B, F)$, and $R B$ ( $C, G)$ were seen, with some CD $45 R O(D, H)$ being expressed. 
form of cytomegalovirus specific IgM. Normal IgG concentrations reflected maternal immunoglobulin. The most striking feature was the markedly reduced expression of CD45 on all leucocytes using a generic CD45 monoclonal antibody. Furthermore, there was minimal expression of the CD45 isoforms RA and RB, with some CD45 RO detected (fig 1). Both parents had normal expression patterns for CD45 (data not shown).

\section{Discussion}

CD45, the common leucocyte antigen, is expressed on all nucleated haematopoietic cells. It has a pivotal role in antigen stimulation of $\mathrm{T}$ lymphocytes and thymic proliferation and exists as a variety of isoforms that are formed by variable splicing of exons 4,5 , and 6 of the CD45 gene and mediate different functions. ${ }^{12}$ This child had low $\mathrm{T}$ cell numbers with normal $B$ cell numbers and associated impairments of cell mediated and humoral immunity. All nucleated haematopoietic cells had abnormal expression of CD45 and the pattern of isotype expression suggests a structurally abnormal form of the molecule. Although SCID with abnormalities in CD45 has never been described in humans, mice deficient in exon 6 of the gene for CD45 have a very similar phenotype, with low $\mathrm{T}$ cell and normal $\mathrm{B}$ cell numbers. ${ }^{2}$ We propose that this is a novel immunodeficiency, further analysis of which may increase our understanding of the functions of this important molecule.

\section{Key messages}

- Disseminated cytomegalovirus infection is usually associated with immunodeficiency

- The absolute lymphocyte count is low in the majority of cell mediated immunodeficiencies

- Active cytomegalovirus infection is a poor prognostic feature in bone marrow transplantation

- Molecular characterisation of novel immunodeficiencies may give insights into the normal functioning of the immune system

We would like to thank Drs M Dillon and M Rossiter for their contribution to the clinical care of this patient.

1 Trowbridge IS, Thomas ML. CD45: an emerging role as a protein tyrosine phosphatase required for lymphocyte activation and development. Anпu Rev Immunol 1994;12:85116.

2 Kishihara K, Penninger J, Wallace VA, et al. Normal B lymphocyte development but impaired $\mathrm{T}$ cell maturation in CD45-exon 6 protein tyrosine phosphatase-deficient mice. Cell 1993;74:143-56. 